From the American

Board of Family Medicine

Ann Fam Med 2019;17:280-282. https://doi.org/10.1370/afm.2346.

\section{NUMBERS MATTER}

In 2018, Family Medicine for America's Health

(FMAH) set a goal for increasing the proportion of US medical school graduates choosing family medicine to $25 \%$ by the year 2030 . Although likely an underestimate based on international comparisons ${ }^{1}$, this is a bold goal, inspired by the substantial contributions a robust primary care workforce can make in improving individual and population health.

Numbers matter, however, and it is important to consider how such an ambitious goal could be achieved. Using estimates from the Association of American Medical Colleges ${ }^{2}$ as well as the American Association of Colleges of Osteopathic Medicine ${ }^{3}$, and taking into account the significant growth in size and number of both Allopathic and Osteopathic medical schools, a reasonable estimate is that a goal of $25 \%$ of US medical students will represent approximately 12,000 new residents in Family Medicine. Given that the current mean size of family medicine residencies is 19.6 residents, ${ }^{4}$ this goal implies the need for approximately 600 new residencies to be established in the next decade, a rate greater than family medicine in its first decade.

This number is daunting. In January, the Working Party - the biannual meeting of the leadership and executive staff of the 8 professional organizations in Family Medicine-convened to discuss approaches to meeting the Graduate Medical Education (GME) implications of the $25 \times 2030$ goal. The group identified 5 key questions.

\section{Funding Source for New Residencies}

In the ongoing dialogue about the cost of GME training $^{5.7}$ an often-quoted figure of $\$ 150,000 /$ resident per year represents a price tag of approximately $\$ 1.8$ billion. This is sizeable compared to current title VII funding ( $\$ 48.9 \mathrm{M} /$ year) or the amount of the recent HRSA grants for rural residencies ( $\$ 25 \mathrm{M}$ over 2 years), but quite small compared with the overall US health care spend.

Should our strategy for advocacy change? At the dawn of Medicare, there was a clear understanding of the social accountability of residency training ${ }^{8-10}$ — that the purpose of GME was to improve the health of their communities. In the context of continued poor health outcomes $^{11}$ and high cost of US health care ${ }^{12}$, the National Academies have proposed major reform. ${ }^{13}$ In this context, the American Academy of Family Physicians engagement in GME expansion at the national level is positive. However, it will also take state and local advocacy to meet this critical need, as highlighted by the rapidly growing GME initiative. ${ }^{14}$ State Medicaid funding is also a critical lever. A final leg of the triad are growing regional health systems, which are beginning to invest in family medicine residencies to develop the workforce they need for population health. The question for our specialty is how to support advocacy, not just in Washington but also state by state, and health system by health system.

\section{Model and Cost of Training}

Should we continue the model of training we've had for 50 years? Some have argued for allowing variability of scope of training and length of residency based on demonstrated competency. Given literature that demonstrates higher quality and lower costs associated with higher rates of continuity and comprehensiveness ${ }^{15,16}$ and a recent JAMA publication that shows longer life expectancy with greater levels of primary care, ${ }^{17}$ any further reduction in the current scope of practice of family physicians seems counterproductive. The initial sense of Working Party participants was that we should preserve broad scope in residency training, while adding curricular flexibility. The American Board of Family Medicine (ABFM) is funding the evaluation of a formal comparison of 4- vs 3-year residency duration and believes that comprehensiveness is critical to fulfilling our contract with society.

In many health system c-suites, family medicine residency training seems costly. This is largely an issue of cost accounting - family medicine residencies often shoulder the operating costs of their family medicine centers, while surgical residencies do not typically have to pay the costs of the operating rooms they use. That issue aside, should we try to reduce the costs of our training programs as we scale up? One possibility is to increase the size of our residency networks: larger residencies might allow fixed costs to be spread over more residents. Internal medicine and Canadian family medicine residency systems already do this. ${ }^{4}$ Although there is much to learn, it remains important for us to consider alternative models for the future. An opportunity for redesign of our training model will be the major revision of RC-Family Medicine requirements in several years.

\section{Increasing the Attractiveness of Family Medicine Residencies}

A third major consideration is that, despite the promise of the Affordable Care Act, and despite broad agree- 
ment about the importance of primary care, great demand for family physicians, and rapidly increasing salaries, the actual number of US medical students choosing family medicine has grown only modestlyand this year declined $!^{18}$ A common explanatory narrative within the specialty is that lower pay and an informal bias against family medicine are major impediments. Yet Psychiatry faces similar challenges and has experienced explosive growth over the last 5 years. ${ }^{19}$ We must ask what changes within Family Medicine residencies and the discipline would make the specialty more attractive to the best medical students? At the Working Party there was a strong sense that curricular flexibility is critical, but there are many other issues. The Accreditation Council for Graduate Medical Education has emphasized the importance of duty hours, and the American Board of Medical Specialties has reported to ABFM student concerns about the absence of a formal parental leave policy on our web page. ABFM will address this specific issue soon, but we must work collectively to demonstrate more broadly our resident-centered approach.

\section{Substantial Expansion of Residents Will Require a Substantial Expansion of Faculty}

Residency faculty are the front line for recruiting excellent residents; how will we recruit, develop, and retain them? It will be important that faculty compensation and support keeps pace with that of community physicians. It is also is vital to begin identification and recruitment of those residents with the right clinical and teaching skills and the calling to be an educator. It may also be helpful to publicize other rewards of faculty jobs, such as the opportunity to nurture younger colleagues, retain a broad scope of practice, advance the scholarship of family medicine, and the stimulation that comes with regularly being challenged by questions. We look forward to seeing the results of the new programs focused on faculty recruitment and retention that the Association of Family Medicine Residency Directors, Society of Teachers of Family Medicine, and Association of Departments of Family Medicine are putting in place. An affirming sign is the enormous proportion of recent graduates who are, in some way, teaching_- $78 \%$ nationally ${ }^{20}$ _ year after year.

\section{What Jobs Will Look Like in the Future}

ABFM graduate survey data have demonstrated that there is a growing gap between what residents want to do, are trained to do, and the jobs which are offered. ${ }^{21}$ Recent data also suggest an association between broad scope of practice and reduced burnout rates among new board-certified family physicians ${ }^{22,23}$ and between employment, lower scope of care, and higher rates of burnout. The less we look like the full scope, patientand family-centered discipline we were in our original charter, the more vulnerable we become as a specialty and the less we are able to support the high quality, lower cost, more personalized care that the nation needs. ABFM finds hope from regions (such as the Boston area) and organizations (such as Kaiser Northern California) where the desire to recruit family physicians combined with our residency requirements has had the effect of reintroducing broader scope family medicine. A critical first step is to call out the problem and develop an intentional strategy across all Family Medicine organizations to work with health systems, CINs, ACOs, and other employers to develop jobs that are both attractive to graduates and offer more in a value-based model of care.

Our intent is not to provide definitive answers but to emphasize the questions and opportunities for new kinds of solutions. We seek collaborative impact across family medicine organizations. Coordinated action, along with support for producing the other health professionals and physicians necessary for a robust primary care system is critical to improving the health of the public.

Warren P. Newton, MD, MPH
Elizabeth Baxley, MD
American Board of Family Medicine

\section{References}

1. Twentieth Report Advancing Primary Care. https://www.hrsa.gov/ advisorycommittees/bhpradvisory/cogme/Reports/twentiethreport. pdf. Accessed Apr 1, 2019.

2. Results of the 2017 Enrollment Survey. https://store.aamc.org/ results-of-the-2017-medical-school-enrollment-survey.html. Accessed Mar 28, 2019.

3. Shannon S. Estimate of Osteopathic Medical Students Graduating by Year 2030. In:2019.

4. GME Data Resource Book 2017-2018. https://www.acgme.org/ About-Us/Publications-and-Resources/Graduate-Medical-EducationData-Resource-Book/articleid/5313. Accessed April 1, 2019.

5. Regenstein M, Nocella K, Jewers MM, Mullan F. The cost of residency training in teaching health centers. N Engl J Med. 2016; 375(7):612-614.

6. Pauwels J, Weidner A. The cost of family medicine residency training: impacts of federal and state funding. Fam Med. 2018;50(2): 123-127.

7. Ashkin EA, Newton WP, Toomey B, Lingley R, Page CP. Cost of incremental expansion of an existing family medicine residency program. Fam Med. 2017:49(7):544-547.

8. Hopkins D. The AMA and U.S. Health Policy Since 1940.http://www. ncbi.nlm.nih.gov/pmc/articles/PMC1306011/pdf/westjmed001740125a.pdf. Published 1985. Accessed Mar 28, 2019.

9. Coggeshall LT. Planning for Medical Progress Through Education. Report to the Association of American Medical Colleges. Evanston, IL: Association of American Medical Colleges: 1965.

10. Newton W, Wouk N, Spero JC. Improving the return on investment of graduate medical education in North Carolina. NC Med J. 2016; 77(2):121-127. 
11. U.S. Health in International Perspective: Shorter Lives, Poorer Health. Washington, DC: National Research Council and Institute of Medicine of the National Academies; 2013.

12. OECD. Stat: Health Expenditure and Financing. https://stats.oecd. org/Index.aspx?DataSetCode=SHA. Accessed Apr 1, 2019.

13. Institute of Medicine. Graduate Medical Education That Meets the Nation's Health Needs. https://www.nap.edu/read/18754/chapter/1. Published 2014. Accessed Apr 1, 2019

14. The GME Initiative Medical Education for America's Health. https:// www.gmeinitiative.org/. Accessed Apr 1, 2019.

15. Bazemore A, Petterson S, Peterson LE, Phillips RL Jr. More comprehensive care among family physicians is associated with lower costs and fewer hospitalizations. Ann Fam Med. 2015;13(3):206-213.

16. Bazemore A, Petterson S, Peterson LE, Bruno R, Chung Y, Phillips $\mathrm{RL}$ Jr. Higher primary care physician continuity is associated with lower costs and hospitalizations. Ann Fam Med. 2018;16(6):492-497.

17. Basu S, Berkowitz SA, Phillips RL, Bitton A, Landon BE, Phillips RS. Association of primary care physician supply with population mortality in the United States, 2005-2015. https://jamanetwork-com. libproxy.lib.unc.edu/journals/jamainternalmedicine/fullarticle/27243 93?resultClick=1. Published 2018. Accessed Apr 1, 2019.

18. American Academy of Family Physicians. 2019 match results for family medicine. https://www.aafp.org/medical-school-residency/ program-directors/nrmp.html. Accessed March 29, 2019.

19. Moran MUS. Seniors matching to psychiatry increases for sixth straight year. https://psychnews.psychiatryonline.org/doi/full/10.1176/ appi.pn.2018.4a3. Published 2019. Accessed Apr 1, 2019.

20. National Family Medicine Residency Graduate Reports. https:// www.theabfm.org/research/national-family-medicine-residencygraduate-reports. Accessed Apr 1, 2019.

21. Coutinho AJ, Phillips RL Jr, Peterson LE. Intended vs reported scope of practice-reply. JAMA. 2016;315(20):2234-2235.

22. Tong ST, Hochheimer CJ, Barr WB, et al. Characteristics of graduating family medicine residents who intend to practice maternity care. Fam Med. 2018;50(5):345-352.

23. Weidner AKH, Phillips RL Jr, Fang B, Peterson LE. Burnout and scope of practice in new family physicians. Ann Fam Med. 2018;16(3):200-205.

\section{STFM FOUNDATION GIVES GRANTS TO 3 STFM COLLABORATIVES}

The STFM Project Fund encourages STFM Collaboratives and Special Project Teams to plan, develop, implement, evaluate, and disseminate findings from education-related scholarly projects. Awarded projects are expected to also provide students, residents, and new faculty an opportunity to participate in a significant way in a scholarly project that exposes them to STFM. This year, the STFM Foundation has chosen to provide $\$ 15,000$ in grants to the following projects.

\section{Project: Beginning Writing Skills for Early Career Minority Faculty}

This project is a 2-year extension of the writing workshops from STFM. The steering committee of the STFM Multicultural and Minority Health $(\mathrm{MMH})$ Collaborative will take on 6 new junior faculty members and actively mentor them from writing a letter to the editor to completing their first manuscript based on their published letter to the editor. Those faculty members will receive help in finding data sources, completing the IRB application, analyzing the data, and writing the manuscript.

"Writing skills for early career minority faculty are a must, not only to share work products from teaching, clinical and research missions, but also to support academic freedom and professional growth," said MMH Steering Committee member Kendall Campbell, MD, The Brody School of Medicine at East Carolina University.

The Collaborative was awarded $\$ 8,000$ for the project. "Without the generosity of the foundation, and the URM fund, it would've been impossible for us to be of service to our colleagues. Underrepresented minorities in medicine (URM) face multiple additional challenges to advancement in academic medicine when compared to their non-URM peers in all medical specialties including family medicine. We are delighted to offer this service to our colleagues to help them prepare for advancement and academic medicine," said the project's Principal Investigator Jose Rodriguez, MD, University of Utah Health Sciences.

The mentored faculty members will be encouraged to present at 2 conferences and use those presentations to inform the scholarly project.

\section{Project: Creation of a National Addiction Medicine Curriculum for Family Medicine Residency Programs}

The STFM's Addictions Collaborative was awarded $\$ 6,000$ over 2 years to create a national addiction medicine curriculum accessible to family medicine residency programs across the country seeking to launch a first-time curriculum or improve an existing one.

"This funding will help jumpstart efforts to develop national curriculum to train residents and faculty in addiction medicine. We hope the curricula and associated faculty development tools will fill a much-needed family medicine curricular void, helping physicians feel more competent and confident in treating patients who struggle with addiction while combating our current opioid epidemic," said the project's Principal Investigator Randi Sokol, MD, MPH, MMedEd, Tufts Family Medicine Residency, Malden, Massachusetts. 